\title{
Immediate Outcomes of Balloon Angioplasty for Coarctation of the Aorta in infants and children
}

\author{
TEHMINA KAZMI, UZMA KAZMI, S. SALMAN A. SHAH, SYED NAJAM HYDER, MUHAMMAD MAISAM ALI, SAEDAH ASAF, MASOOD \\ SADIQ \\ Department of Cardiac Surgery \& Cardiology, Children's Hospital and Institute of Child Health Lahore, \\ Correspondence to Dr. Tehmina Kazmi, Assistant Professor Paed. Cardiology, Email: drtehminakazmi@gmail.com, Cell: +92-331-4669772
}

\begin{abstract}
Background: Coarctation of the aorta (CoA) is one amongst commonest congenital heart diseases (CHD) which reuires early intervention to avoid morbidity and mortality. Balloon angioplasty (BA) can be offered in place of surgery in selected cases.

Aim: To evaluate the safety of procedure and efficacy of catheter intervention balloon angioplasty for CoA as an alternative to surgery and to identify the factors related with poor outcome of the intervention in infants and children Methods: The study was a retrospective observational cohort study of 46 infants and children undergoing BAS during a six-year period (Jan 2014 to May 2020). Demographic detail history and investigation including echo and ECG were collected for all the patients. Immediate pre and post procedure complications were noted.

Results: Forty six (46) children and infant patients, underwent balloon angioplasty 29 were male and 17 were female. Patients were divided into two groups. Group A included patient with successful outcome and group B included those with suboptimal results. Characteristics of both groups we studied. In group A the median age was 6.3 years and median weight was $15 \mathrm{~kg}$ whereas in group B median age was 3.5 years and median weight was 9 $\mathrm{kg}$. Forty patients had native CoA $(86.9 \%)$ while six patients were post op $(13 \%)$. There was no mortality. One patient had a small aneurysmal formation (3\%). Four patients had a transitive loss of pulse. Thirty-four patients had a successful outcome $(73.9 \%)$ while twelve patients had a suboptimal result $(26 \%)$.

Conclusion: Coarctation angioplasty has good early outcome and it can be considered as a sustainable alternative to surgery in critical infants and children patients high risk of mortality with surgery. wise selection of patients, use of improved low-profile catheters and better patient care can reduce the complications and incidence of mortality.

Keywords: Coarctation, Balloon angioplasty
\end{abstract}

\section{INTRODUCTION}

Severe Coarctation of the aorta (CoA) is a congenital cardiac disease that causes narrowing of descending aorta and obstruction of blood flow in the aorta. Usually CoA is just distal to the left subclavian artery at the point where ductus arteriosus attaches to the aorta. It involves thickening of intima media with 'shelf-like' tissue projecting in the lumen of the aorta from the posterior wall ${ }^{1}$.

Overall incidence of CoA is 4 per 10,000 live births and $26-8 \%$ of all CHDs with male preponderance. Congenital bicuspid aortic valve is the commonest associated CHD approximately $45-62 \%{ }^{3}$. The outcome of unrepaired coarctation was extremely poor during the presurgical era. Median survival age was 31 years and a quarter of patients could not survive till age of 20 years $^{4}$. Untreated CoA can lead to complications such as congestive heart failure, systemic hypertension, and poor perfusion to the lower body $^{5}$.

Successful surgical correction of CoA through end-toend anastomosis (EEA) was first described by Crafoord and Nylin in $1945^{6}$. Subsequent advances in techniques, including end-to-end anastomosis, extended end-to-end anastomosis, subclavian flap repair, interposition graft, and coarctation resection with prosthetic patch augmentation allowed correction of more complex anatomical variants ${ }^{7}$. Catheter intervension for CoA angioplasty with balloon (BA) was introduced in the early $1980 \mathrm{~s}^{8}$. As a result, prognosis of

Received on 11-02-2021

Accepted on 17-06-2020 this disease has significantly improved, with majority patients surviving into adulthood. However, patients may need frequent checkups for improvement in associated problems like persistent hypertension, re-coarctation, and formation of small aneurysm during procedure ${ }^{9}$.

No significant difference has been found between the effectiveness of PTA and surgery for $\mathrm{CoA}^{10}$. However, PTA is preferred for treating critically ill patients with severe LV dysfunction, mitral regurgitation, or low cardiac output, regardless of age ${ }^{11}$. It is also an accepted option for treating post-operative re-coarctation ${ }^{12}$. Finally, longer waiting list and hospital stay following surgery in our tertiary-care setting increase preference for BA.

The objective of this study is to find out the efficiency and safety of BA and identify factors associated with a poor outcome following BA for CoA. It will also compare the outcome of BA in patients with native and postop CoA.

\section{METHODOLOGY}

This study is a retrospective cohort conducted in one centre that included all patients who presented with severe CoA to The Children's Hospital from May 2014 to February 2020 after approval from Hospital Ethical Committee. All patients underwent diagnostic transthoracic echocardiography and catheterization. Patients amenable to surgery were excluded. 54 patients were identified with CoA on the basis of having an instantaneous pressure gradient greater than or equal to $20 \mathrm{mmHg}$. All patients were matched for age, gender, weight, and severity of CoA. No personal or identifiable data was declared. 
Inclusion Criteria: All patients who underwent balloon angioplasty for CoA in the angiography department of Children's Hospital Lahore (CHL) during January 2014 to May 2020 were included in the study.

Exclusion Criteria: Patients diagnosed as having complex and cyanotic congenital heart disease along with CoA were excluded from study.

Procedure: After taking history and physical examination, the patients underwent cardiac catheterization through the femoral artery. Right aortogram in $45^{\circ}$ left anterior oblique(LAO), $20^{\circ}$ cranial and $30^{\circ}$ right anterior oblique, $0^{\circ}$ cranial configurations were performed. In addition, peak-topeak gradient across the coarctated segment was recorded. We selected balloon (Tyshak II, Cordis or Z-Med Balloon) 23 times greater than narrowed segment for angioplasy. The balloon was positioned across coarctated segment and fully inflated till complete disappearance of waist. Measurements were carefully recorded of narrow segment, distal transverse arch, and descending aorta. Post-procedure right aortogram was performed to record hemodynamics. Outcome of the procedure was termed successful if the pressure gradient was reduced to at least $50 \%$ of the original.

Statistics: All analysis was carried out using SPSS 20. Demographic data was recorded. All Complications during procedure and immediated post procedure were also noted. Kolmogorov-Smirnov test was applied to check for normality assumption. Mean $\pm S D$ were calculated for all quantitative variables with normal distribution including pressure gradient, narrow point, balloon size, width of transverse arch, and width of the descending aorta. Median with range was calculated for non-normal distribution variables including age and weight. Independent t-test was used to determine significant difference between quantitative variables in both groups. Chi square test was used to determine significant difference in categorical variables in both groups.

\section{RESULTS}

Group A ( $n=34)$, Male: female ratio: $2.4: 1$

\begin{tabular}{|l|c|c|}
\hline & Median & Range \\
\hline Age & 6.3 & 14 \\
\hline Weight & 15 & 47 \\
\hline Pre-Gradient & Mean & SD \\
\hline Post-Gradient & 37.44 & 18.97 \\
\hline Percentage Difference & 13.26 & 10.61 \\
\hline Narrow Point & 64.44 & 22.22 \\
\hline Balloon Size & 3.90 & 2.00 \\
\hline Transverse Arch & 9.44 & 2.81 \\
\hline Descending Aorta & 10.48 & 3.39 \\
\hline
\end{tabular}

Ejection fraction: $60 \% 30$. Less than $60 \% 4$ Group B $(n=12)$, Male: female ratio: $3: 1$

\begin{tabular}{|l|c|c|}
\hline & Median & Range \\
\hline Age & 3.55 & 12 \\
\hline Weight & 9 & 21 \\
\hline & Mean & SD \\
\hline Pre-Gradient & 32.50 & 17.56 \\
\hline Post-Gradient & 33.17 & 13.17 \\
\hline Percentage Difference & -12.5 & 37.92 \\
\hline Narrow Point & 3.60 & 1.49 \\
\hline Balloon Size & 8.42 & 2.47 \\
\hline Transverse Arch & 9.03 & 2.58 \\
\hline Descending Aorta & 9.58 & 2.80 \\
\hline
\end{tabular}

Ejection fraction: $60 \% 12$

\section{DISCUSSION}

Coarctation of aorta is one of the commonest congenital heart disease that can be life threatening in infants so needs early intervention to save patients. Coarctation of aorta accounts for $6-8 \%$ of congenital heart defects. Like in various stenotic lesions (pulmonary and aortic valvar stenosis, branch pulmonary artery stenosis and post-surgery re-coarctation) balloon angioplasty has become first choice in the treatment. The use of catheter intervention technique in infants for native CoA became restricted and was controversial previously due to the reported incidence of early recoarctation ${ }^{5-7}$ and, in certain, the development of aneurysms in the angioplasty spot $^{8-11}$. But, several centers continued to use balloon angioplasty as the treatment of choice for localized coarctation and found its efficacy.

In our study the study total 46 patients were included and successful outcome (post CoA ballooning pressure gradient across COA $<20 \mathrm{mmHg}$ ) observed in 34 patients $(75.5 \%$ ). Mean gradient in this group was $37.44 \mathrm{mmHg}$ pre procedure and it reduced to $13.26 \mathrm{mmHg}$ after balloon angioplasty of coarctation. In a study conducted by Moreno et al the result reported (i.e., pressure gradient across CoA, $<20 \mathrm{mmHg}$ ) in total $18 / 26$ patients in CoA angioplasty group $(69.2 \%)^{13}$. Shah et al reported twenty-five out of 26 neonates $(96 \%)$ had successful immediate outcome of balloon dilatation. ${ }^{14}$ Similar results were reported by Yetman et $\mathrm{al}^{8}$. There was significant decrease in mean gradient and increase in mean diameter of narrowest segment immediately after the procedure ${ }^{15}$. Similar success rate has been reported by Farouk et al in their study in immediate post procedure period $^{16}$.

In our study 12 patients had a sub optimal result as there was no significant fall in pressure gradient post ballooning. On retrospective analysis the only difference found between these two groups of patients was the difference in ratio between balloon size and narrow point. In the successful group (group A) the balloon to narrow point ratio was $3: 1$. There were 34 patients in this group. In (group B) in whom there was no significant fall in post ballooning gradient across coarctation segment patients the balloon to narrow point ratio was $2: 1$. Rest of the demographic details were same. Median age in successful group was 6.3 years. Median weight was $15 \mathrm{~kg}$. In the less successful group median age was $3.5 \mathrm{yr}$ and median weight was $9 \mathrm{~kg}$.

In our study in both groups the balloon size was selected in reference to narrow point. Mean narrow point was $3.9 \mathrm{~mm}$ and median balloon size used was $9.44 \mathrm{~mm}$. Transverse arch size was $10.48 \mathrm{~mm}$ and descending aorta was $10.14 \mathrm{~mm}$. In group a balloon CoA ratio was $3: 1$ and in group 'B' it was $2: 1$. There was significant difference in post coarctation gradient in both groups. In group 'A' there was significant fall but in group ' $B$ ' there results were not optimal. In similar study conducted by Doshi average size of balloon used was $162 \%$ of isthmus size and $110 \%$ of diameter of descending thoracic aorta at the level of diaphragm and no significant correlation was observed in occurrence of restenosis. Eight patients had re-intervention like balloon dilatation while 1 patient required surgical arch repair.

In patients with LV dysfunction due to coarctation balloon angioplasty is a preferred salvage procedure as 
compared to surgery where surgical risk is high and recovery is slow. In our patients due to long standing coarctation 4 patients develop left ventricle dysfunction EF < $60 \%$. In most of patients LV functions were normal EF was $>60 \%$. There was no difference in out-come in terms of post coarctation angioplasty gradient, aneurysm formation and LV dysfunction post procedure recovery and hospital stay in both these groups. LV functions improved a little bit in patients with LV dysfunction. Similarly, Beekman et al also reported higher incidence of morbidity and mortality with associated cardiac anomalies and left ventricular dysfunction in their study ${ }^{17}$.

A notable difference in the recovery of LV function following surgery versus balloon angioplasty has been reported. All patients with severe LV dysfunction at presentation had complete recovery to normal function on follow-up after surgical repair. In patients after balloon angioplasty among those with severe LV dysfunction pre angioplasty, one patient significantly improved after intervention and had mild LV dysfunction after angioplasty, five patients had persistent moderate LV dysfunction, and three patients had persistent severe LV dysfunction on follow-up. Residual coarctation on pre-discharge echocardiogram was observed in two of the eight patients with persisting moderate or severe LV dysfunction ${ }^{20}$.

Regarding complications in our both groups there was no mortality, only one patient in group A developed small aneurysm immediately after ballooning but patient was hemodynamically stable throughout. All patients were given anticoagulation before proceeding and only two patients temporarily lost pulses which recovered with proper anticoagulation therapy in next 12 hours. Beekman et al reported injuries at prick site in femoral arteries. Arterial thrombosis and loss of pulses seen in $21 \%$ of newborns and infants, and in $9 \%$ of children in their study ${ }^{14}$. Similarly, in our study $9.0 \%$ infants had transient loss of femoral pulse which was reestablished within 24 hours with adequate anticoagulation.

Other associated cardiac anomalies also affect outcome in coarctation of aorta ${ }^{18}$. In our study group 7 patients (15\%) has bicuspid aortic valve and mild to moderate aortic stenosis. We didn't find any impact of it on outcome. In a study by Shah et al acyanotic congenital heart defects were seen in $36.36 \%$ patients while $2.2 \%$ patients had complex cyanotic congenital heart disease. One patient died 4 days after procedure due to septicemia, had associated large ventricular septal defect with severe pulmonary artery hypertension ${ }^{14}$.

\section{CONCLUSION}

Coarctation angioplasty has good early outcome and it can be considered a viable alternative to surgery especially in seriously ill patients with high risks of mortality during surgery. Careful selection of suitable patients, use of improved technique low-profile catheters, and better patient care can reduce the incidence of morbidity and mortality.

Recommendations: In a developing country with limited resources we recognized 3:1 size balloon for $\mathrm{CoA}$ in order to reduce the chance of suboptimal results and re-intervention.

\section{REFERENCES}

1. Natural history of coarctation of the aorta. Campbell M. Br Heart J. 1970;32:633-640.

2. Hypoplasia, pseudocoarctation and coarctation of the aorta - a systematic review. Singh S, Hakim FA, Sharma A, et al. Heart Lung Circ. 2015;24:110-118.

3. Doshi, Arpan R, and Sathish Chikkabyrappa. "Coarctation of Aorta in Children." Cures vol. 10,12 e3690. 5 Dec. 2018, doi:10.7759/cureus.3690

4. Nguyen L, Cook SC. Coarctation of the Aorta: Strategies for Improving Outcomes. Cardiol Clin. 2015;33(4):521-vii. doi:10.1016/j.ccl.2015.07.011

5. Suradi H, Hijazi ZM. Current management of coarctation of the aorta. Glob Cardiol Sci Pract. 2015. 2015 (4):44.

6. Crafoord C, Nylin G. Congenital coarctation of the aorta and its surgical treatment. J Thorac Surg 1945; 14:347-61.

7. Surgical management of aortic coarctation in adolescents and adults. Yin K, Zhang Z, Lin Y, et al. Interact Cardiovasc Thorac Surg. 2017;24:430-435.

8. Transluminal aortic balloon angioplasty for coarctation of the aorta in the newborn. Singer MI, Rowen M, Dorsey TJ. Am Heart J. 1982;103:131-132.

9. Aortic coarctation repair in the adult. Cardoso $G$, Abecasis M, Anjos R, Marques M, Koukoulis G, Aguiar C, Neves JP. J Card Surg. 2014;29:512-518.

10. Alaei, Fariba et al. "Balloon Angioplasty versus Surgical Repair of Coarctation of Aorta in Infants." The journal of Tehran Heart Center vol. 6,3 (2011): 134-7.

11. Suradi, Hussam, and Ziyad M Hijazi. "Current management of coarctation of the aorta." Global cardiology science \& practice vol. 2015,4 44. 18 Nov. 2015, doi:10.5339/gcsp.2015.44

12. Beekman RH., III . Coarctation of the aorta. In: Allen HD, Driscoll DJ, Shaddy RE, Feltes TF, editors. Moss and Adams' Heart Disease in Infants, Children and Adolescents. 7th ed. Philadelphia: Lippincott William \& Wilkins; 2008. pp. 987-1004

13. Del Cerro, M., Fernández-Ruiz, A., Benito, F., Rubio, D., Castro, M. and Moreno, F., 2005. Balloon Angioplasty for Native Coarctation in Children: Immediate and Medium-Term Results. Revista Española de Cardiología (English Edition), 58(9), pp.1054-1061.

14. Nilesh Oswal, Dhaval Doshi, Nikhil Jadhav, Dhammdeep Humane, Kamal Sharma, Komal Shah (2017) 'Balloon dilatation of native coarctation of aorta in infants - short term clinical result', PEDIATRIC REVIEW: INTERNATIONAL JOURNAL OF PEDIATRIC RESEARCH, VOL 4 (1), pp. 53-58.

15. Yetmen yetman at, nykanen $\mathrm{d}$, mccrindle bw, sunnegardh $\mathrm{j}$, adatia $\mathrm{i}$, freedom rm, benson I. Balloon angioplasty of recurrent coarctation. J am card. 1997; 30(3):811-16. Doi: http://dx.doi.org/10.1016/s0735-1097(97)00228-3.

16. Ferouk mohammed farouk, ahmed el ayadi, sonia el saeidy. Improvement of left ventricular mass following balloon angioplasty of native coarctation of the aorta: midterm follow-up in cairo university, children's hospital. Br j med med res. 2013; 3(4): 127184. Doi: $10.9734 / \mathrm{bjmmr} / 2013 / 3262$.

17. Beekman rh, rocchini ap, dick $m$ 2nd, snider ar, crowley dc, serwer ga, spicer rl, rosenthal a. Percutaneous balloon angioplasty for native coarctation of the aorta. J am coll cardiol. 1987; 10(5):107884. [pubmed]

18. Webb gd, smallhorn $\mathrm{jf}$, therrien $\mathrm{j}$, redington an. Congenital heart disease. In: bonow ro, mann dl, zipes $\mathrm{dp}$, and libby $\mathrm{p}$ (eds). Braunwald's heart disease: a textbook of cardiovascular medicine, 9th edition. Philadelphia, wb saunders. 2011; 65:141267. [pubmed]

19. Ovaert c, mccrindle bw, nykanen d, macdonald c, freedom $\mathrm{rm}$, benson In. Balloon angioplasty of native coarctation: clinical outcomes and predictors of success. J am coll cardiol. 2000; 35(4): 988-96. Doi: http://dx.doi.org/10.1016/s0735-1097(99)00646-4.

20. Sehar T, Qureshi AU, Kazmi U, Mehmood A, Hyder SN, Sadiq M. Balloon valvuloplasty in dysplastic pulmonary valve stenosis: immediate and intermediate outcomes. J Coll Physicians Surg Pak. 2015 Jan;25(1):16-21. PMID: 25604363. 